\title{
Issues of Electronic Waste on Life - A Reality
}

\author{
${ }^{1}$ Saurabh Mitra, ${ }^{2}$ Dr. Jayati Chatterjee Mitra \\ ${ }^{1}$ Associate Prof. Dept. of ECE, ${ }^{2}$ Associate Prof. Dept of Chemistry \\ Dr. C.V. Raman University, Bilaspur, Chhattisgarh, India
}

\begin{abstract}
Electronic waste or e-squander is one of the quickest developing issues of the world. E-squander involves a large number of parts, some containing poisonous substances that can adversely affect human wellbeing and the earth if not dealt with legitimately. In India, e-squander the board expect more noteworthy essentialness not just because of the age of its own e-squander, yet additionally as a result of the dumping of e-squander from created nations. This is combined with India's absence of proper foundation and methods for its transfer and reusing. The generation of electrical and electronic gear (EEE) is one of the quickest developing worldwide assembling exercises. Quick monetary development, combined with urbanization and developing an interest for customer merchandise, has expanded both the utilization and the creation of EEE. The Indian data innovation (IT) industry has been one of the real drivers of progress in the economy in the most recent decade and has contributed essentially to the advanced unrest being experienced by the world. New electronic contraptions and machines have invaded each part of our everyday lives, furnishing our general public with more solace, wellbeing, and security and with simple data procurement and trade. The information society anyway is making its own poisonous impressions.
\end{abstract}

Keywords: e-squander, recycling, EEE, IT;

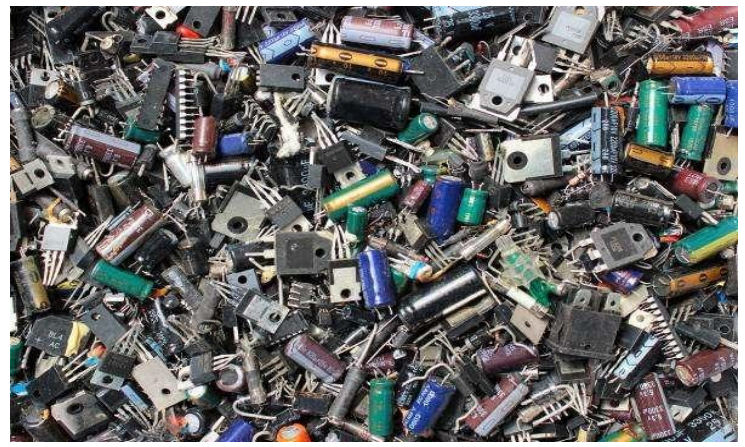




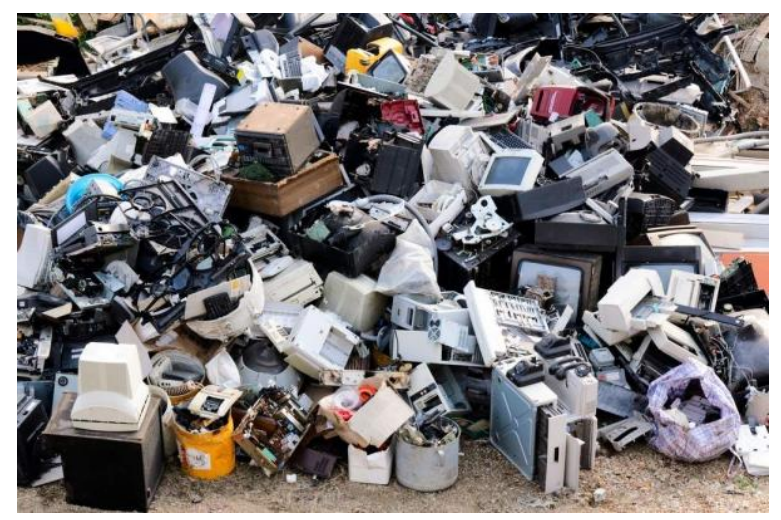

\section{PRESENTATION:}

E-Waste comprehensively covers squander from all electronic and electrical apparatuses and contains things, for example, PCs, cellphones, advanced music recorders/players, coolers, clothes washers,

TVs and numerous other family unit purchaser things. This incorporates utilizing hardware which is bound for reuse, resale, rescue, reusing, or transfer. Others are re-usable (working and repairable gadgets) and optional piece (copper, steel, plastic, and so forth.) to be "products", and hold the expression "squander" for buildup or material which is dumped by the purchaser as opposed to reused, including buildup from reuse and reusing tasks. Electronic waste is a name given to any bit of electronic hardware that is toward the finish of its helpful life. A portion of these items can be exchanged, repaired, or disassembled to save resalable products. Others, be that as it may, serve no "valuable" reason and are disposed of.

At the point when these items are esteemed to be toward the finish of their usable life cycle and consequently moved toward becoming e-squander, the appropriate transfer is fundamental because of the unsafe materials a considerable lot of these things contain. E-squander generation is expanding at a disturbing rate, particularly in creating nations which at present don't have the best possible assets or assets to discard it appropriately. Many created nations think that its less expensive and increasingly advantageous to dispatch their e-waste to these creating nations, which just adds to the measure of e-squander experiencing hazardous transfer. Without the legitimate transfer, synthetic substances, for example, lead, arsenic, chromium, and dioxins may filter into nature, causing ecological corruption and represent a risk to people and creatures in the region. Hazardous transfer of e-squander is a developing issue and the natural impacts and human wellbeing risks are intense; an arrangement should be built up to address this issue and maintain a strategic distance from the results.

\section{IsSues IDENTIFIED: ?????}

E-squander and ecological contamination is a worldwide issue. The United Nations recommends that worldwide esquander is set to surpass 40 million tons for every year. End of item life reusing is profoundly dirtying, nonpractical and unregulated in numerous nations. The weight of e-squander not just contaminates the land-fill it is having genuine wellbeing suggestions because of concoction draining into the water table, in the end advancing toward agrarian create and into individuals. As per an ongoing report by the BBC, e-squander contamination is causing extreme wellbeing worries for many individuals around the globe, generally in the creating countries of Africa, Europe, and Asia. Roughly 23 percent of passings in these countries are connected to contamination and other ecological effects. The report additionally reasoned that in excess of 200 million individuals worldwide are in danger of presentation to harmful waste. 


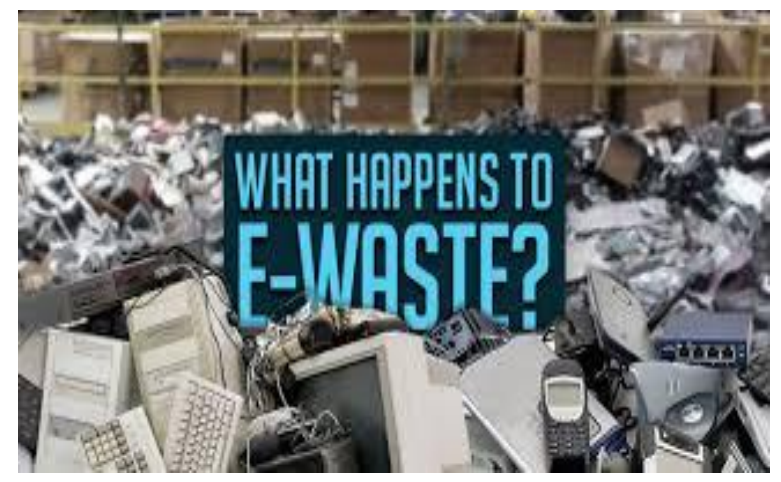

With the utilization of electrical and electronic gear (EEE) on the ascent, the measure of electrical and electronic waste (e-squander) created every day is similarly developing immensely around the world. Reusing of important components contained in e-waste, for example, copper and gold has turned into a wellspring of income, mostly in the casual part of creating or developing industrialized nations. In any case, crude reusing procedures, for example, consuming links for holding the natural copper uncover both grown-up and kid laborers just as their families to a scope of unsafe substances. E-squander associated wellbeing dangers may result from direct contact with destructive materials, for example, lead, cadmium, chromium, brominated fire retardants or polychlorinated biphenyls (PCBs), from the inward breath of dangerous exhaust, just as from the gathering of synthetic compounds in soil, water, and nourishment. In expansion to its dangerous parts, being handled, e-waste can offer ascent to various poisonous sideeffects prone to influence human wellbeing. Moreover, reusing exercises, for example, disassembling of electrical gear may possibly bear an expanded danger of damage.

Kids are particularly powerless against the wellbeing dangers that may result from e-squander introduction and, accordingly, require increasingly explicit security. As they are as yet developing, the kids' admission of air, water, and nourishment in the extent to their weight is altogether expanded contrasted with grown-ups, - and with that, the danger of risky substance ingestion. Moreover, their bodies' practical frameworks, for example, the focal apprehensive, safe, regenerative and stomach related framework are as yet creating and presentation to poisonous substances, by hampering further advancement, may cause irreversible harm. Numerous youngsters are presented to e-squander inferred synthetics in their day by day life because of risky reusing exercises that are regularly directed at their home-either by relatives or by the kids themselves. Besides, kids might be uncovered through dump locales found near their homes, schools and play territories.

Innovation is progressing at an exponential rate; new gadgets are quicker, littler, and progressively helpful to utilize. Shouldn't something be said about that old telephone, PC, or camera that is disposed of in light of the fact that there are more up to date and fresher options? We live in a purchaser driven society that is continually purchasing, overhauling, and supplanting current innovation.

Generation: Not just are we supplanting the innovation that we as of now have, however, the sheer number of new hardware per family unit is developing to stay aware of and keep up the advanced ways of life we have made using these items. The developing measure of delivered electronic gadgets means a substantial increment in e-squander creation. Truth be told, it is assessed that by 2017 , worldwide e-squander creation will increment by $33 \%$, which is roughly 72 million tons

It is assessed that the U.S. produces 400 million e-squander things a year all alone. European Union and Japan family e-squander generation are evaluated at 8.9 million tons and 4 million tons separately, and these e-squander volumes are just expected to increment. Albeit created nations are as of now delivering a lot of e-squander, the rate at which e-squander generation is developing in creating nations is disturbing. For instance, in India, e-squander holds are developing at an exacerbated yearly development rate of 25 percent.

Exportation from created nations: Prior to the 1970's, not many places on the planet had strict controls relating to the transfer of dangerous waste; dumping the loss into landfills was an extremely regular practice. Be that as it may, through the span of the 1970's, many created nations started to favor directions that dealt with the treatment of unsafe waste and synthetic use in the earth, for example, the lethal substances control act, clean water act, and clean 
air act. In consistence with there new control, organizations creating unsafe waste were compelled to invest more energy, cash and asset to discard it legitimately.

\section{Impacts on HUMAN HEALTH and ENVIRONMENT:}

The level of risk presented to laborers and the earth shifts incredibly relying upon the people included and the idea of activities. What is known is that the contamination created by e-squander handling achieves dangerous or genotoxic impacts on the human body, compromising the wellbeing of laborers as well as of current occupants and future ages living in the neighborhood condition. It is obvious from a few examinations that the simple reusing strategies combined with the measures of e-squander handled have just brought about unfavorable ecological and human wellbeing impacts, including debased soil and surface water. Medical issues have been accounted for over the most recent couple of years, including infections and issues identified with the skin, stomach, respiratory tract and different organs. Laborers endure high frequencies of birth abandons, newborn child mortality, tuberculosis, blood sicknesses, inconsistencies in the invulnerable framework, failing of the kidneys and respiratory framework, lung malignant growth, underdevelopment of the cerebrum in youngsters and harm to the anxious and blood frameworks.

Long-run transport of contaminations has likewise been watched, which recommends a danger of auxiliary introduction in remote regions. Barometrical contamination because of consuming and destroying exercises is by all accounts the fundamental driver of word related and optional introduction. Casual segment e-squander exercises are additionally an essential wellspring of condition to natural pecking order pollution, as contaminants may gather in farming terrains and be accessible for take-up by touching animals. What's more, most synthetic substances of concern have a moderate metabolic rate in creatures, and may bio aggregate in tissues and be discharged in palatable items, for example, eggs and drain. E-squander related harmful impacts can be exacerbated all through an individual's lifetime and crosswise overages. E-squander consequently establishes a huge worldwide ecological and wellbeing crisis, with suggestions far more extensive than word related introduction and including powerless gatherings and ages to come.

The electronic and electrical products are generally characterized under three noteworthy heads, as: 'white merchandise,' including family apparatuses like climate control systems, dishwashers, coolers and clothes washers; 'dark-colored merchandise,' containing TVs, camcorders, cameras, and so forth.; 'dim products,' like PCs, printers, fax machines, scanners, and so on. The dark merchandise is similarly increasingly complex to reuse because of their poisonous piece. EEE's are made of a large number of segments, some containing dangerous substances that adversely affect human wellbeing and the earth if not took care of appropriately. Regularly, these perils emerge because of the ill-advised reusing and transfer forms utilized. It can have genuine repercussions for those in nearness to places where e-squander is reused or consumed. Squander from the white and dark colored merchandise is less dangerous as contrasted and dim products. A PC contains profoundly poisonous synthetic substances like lead, cadmium, mercury, beryllium, BFR, polyvinyl chloride and phosphor mixes.

Lead: It applies poisonous consequences for different frameworks in the body, for example, the focal (natural full of feeling disorder) and fringe sensory systems (engine neuropathy), the hemopoietic framework (paleness), the genitourinary framework (fit for making harm all parts of nephron) and the conceptive frameworks (male and female).

Mercury: It makes harm the genitourinary framework (cylindrical brokenness), the focal and fringe sensory systems just as the embryo. At the point when inorganic mercury spreads out in the water, it is changed into methylated mercury, which bio-amasses in living life forms and thinks through the evolved way of life, especially by fish.

Cadmium: It is a possible long haul aggregate toxin. Lethal cadmium mixes aggregate in the human body, particularly in the kidneys. There is proof of the job of cadmium and beryllium in cancer-causing nature.

Polycyclic fragrant hydrocarbons (PAH): It influences lung, skin, and bladder. Epidemiological investigations in the past on word related introduction to PAH give adequate proof of the job of PAH in the enlistment of skin and lung malignant growths.

Inappropriate Electronic Waste Disposal prompts negative impacts of E-squander on Environment Computers to contain lethal materials like zinc, nickel, lead, barium, and chromium, which is the reason it's basic to do legitimate 
PC reusing. Every one of these metals happens in focuses that are higher than the governmentally directed dimensions. Our developing stream of e-squander is a danger to our condition. In 2005 an expected 5.3 billion pounds of electronic waste was created (EPA, 2005). Of this, just 9\% was reused. When we resign our PCs we have four alternatives: to reuse it, give it away, return it to the maker or toss it in the junk. Most usually, we discard it.

Impacts of e-squander on Environment Through Landfills When we toss out our PCs, they end up in landfills, causing the likelihood of harmful metal draining into the groundwater. Lethal metals in e-squander drain into our supply of assets, compromising their honesty. At the point when e-squander is heated up, poisonous synthetic compounds are discharged into the air, harming the environment. E-squander the executives is a basic thought for future ages as legitimate electronic reusing is getting to be more diligently to discover.

Impacts of E-squander on Environments in Third World Countries E-squander antagonistically influences our creating countries. Rather than dependably reusing our electronic gadgets, America sends our e-waste to these nations. The e-squander heaps up in the landfills, which cause mischief to nature in different ways. Poisons from the metals in gadgets are discharged into the climate, and what is more regrettable, when the e-squander transfer isn't financed, the contaminations from our electronic waste can finish up in toys for our kids that are sent back to us. Rather than trading e-waste, or giving it a chance to spoil in landfills, we can help our condition by restoring our electrical items to stores and producers, sending them to capable reusing focuses, pitching them to individuals that will discover them valuable, or giving them to stores, for example, Goodwill gift focus.

\section{The Human and Environmental Effects of E-Waste}

(April 2013) Roughly 40 million metric huge amounts of electronic waste (e-squander) are delivered comprehensively every year, and around 13 percent of that weight is reused generally in creating nations. Around 9 million tons of this waste-disposed of TVs, PCs, cellphones, and different hardware - are delivered by the European Union, as per the United Nations Environment Program (UNEP). What's more, UNEP takes note of that this gauge of waste is likely excessively low.

Casual reusing markets in China, India, Pakistan, Vietnam, and the Philippines handle somewhere in the range of 50 percent to 80 percent of this e-squander, regularly destroying, consuming, and disassembling the items in "lawns." Emissions from these reusing rehearses are harming human wellbeing and nature.

Creating nations with quickly developing economies handle e-squander from created nations, and from their very own interior buyers. Presently, an expected 70 percent of e-squander took care of in India is from different countries, however the UNEP gauges that somewhere in the range of 2007 and 2020, household TV e-waste will twofold, PC e-waste will build multiple times, and mobile phones multiple times.

The casual area's reusing rehearses amplify wellbeing dangers. For instance, essential and optional introduction to dangerous metals, for example, lead, results fundamentally from outdoors consuming used to recover profitable segments, for example, gold. Ignition from consuming e-squander makes a fine particulate issue, which is connected to aspiratory and cardiovascular illness.

While the wellbeing ramifications of e-squander are hard to disconnect because of the casual working conditions, neediness, and poor sanitation, a few examinations in Guiyu, a city in southeastern China, offer knowledge. Guiyu is known as the biggest e-squander reusing site on the planet, and the city's occupants show generous stomach related, neurological, respiratory, and bone issues. For instance, 80 percent of Guiyu's kids encounter respiratory illnesses and are particularly in danger of lead poisoning. 3

Occupants of Guiyu are not by any means the only ones in danger. Scientists, for example, Brett Robinson, an educator of soil and physical sciences at Lincoln University in New Zealand, caution that breeze designs in Southeast China scatter dangerous particles discharged by outdoors copying over the Pearl River Delta Region, home to 45 million people. 4 along these lines, lethal synthetic substances from e-squander enter the "dirt harvest sustenance pathway," a standout amongst the most critical courses for substantial metals' presentation to people. These synthetic concoctions are not biodegradable - they hold on in the earth for extensive stretches of time, expanding introduction chance. 
The Basel Convention on the Control of Transboundary Movements of Hazardous Wastes and Their Disposal bans the trading of dangerous waste, including e-squander, among created and creating nations. The United States is the biggest generator of e-squander worldwide and the main industrialized country not yet approving the Basel Convention.

E-squander is an imperative worldwide ecological and medical problem. Promising approach reactions have emerged from the European Union, which is unquestionably the source as in charge of e-squander. With this methodology, makers are required to take out unsafe poisons from generation.

The outside of the most hardware is made of a mix of plastic, glass and once in a while metal. These materials alone ought not just to finish up in a landfill. Inside, however, the cosmetics of hardware comprises of various synthetics, a significant number of which are cancer-causing. Screens from PCs and TVs just as the circuit sheets contain lead. More up to date level board screens additionally contain mercury. Cadmium, a cancer-causing agent, is found in specific batteries. Different dangerous synthetic compounds found in some gadgets incorporate zinc, chromium, selenium, arsenic, and PCBs or polychlorinated biphenyls. Polyvinyl chloride or PVC as it is usually known as an item with incalculable applications. One of these is the protection of links and wires utilized in hardware. The arrival of chlorinated dioxins is an assurance when these waste items are burned.

\section{Ecological Damage:}

There is nothing more than a bad memory approach to discard gadgets that contain these perilous synthetic compounds. Covering them in the landfill is one way, however, after time the synthetic substances escape from the trashed items and advance into the groundwater. This prompts expanded rate of illness produced by presentation to neurotoxins and cancer-causing agents. Another alternative for waste transfer is burning. This, in any case, is much more terrible than covering them in the ground, for the high temperatures expected to combust the gadgets energize the discharge and dispersal of a considerable lot of similar synthetic concoctions, either as airborne particles, in the fiery debris or in water.

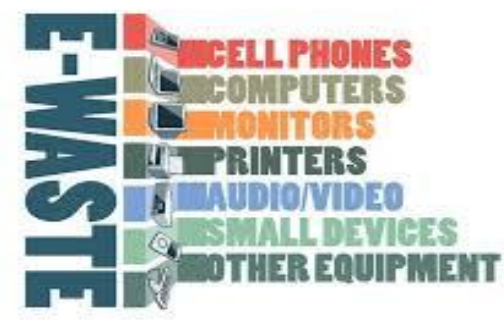

\section{Conceivable SOLUTIONS TO THE E-WASTE:}

Specialized: The answer for the e-squander emergency lies in 'aversion at the assembling source' or the 'prudent rule.' This should be possible by utilizing waste minimization strategies and by a manageable item plan.

Stock Management, Production Process Modification, Volume Reduction, Recovery and Reuse, Sustainable Product Design, Rethinking of strategies for configuration, Use of Renewable Material and Energy, Creating electronic segments and peripherals of biodegradable material, Green Packaging, Minimum Packaging Material

Merchandise exchanges: Producers must be in charge of the whole life cycle of their items. In created nations, a few endeavors have been made on this front. A few dozen urban communities in the conditions of California and Massachusettes, including San Francisco, additionally have passed goals supporting 'maker reclaim' rules. Wipro Infotech has propelled an e-squander transfer benefit for end clients. Others offering reusing alternatives incorporate Dell, HP, and Apple. 


\section{Natural and Human Health of E-Waste}

Casual reusing causes serious ecological and human wellbeing impacts that should be tended to and controlled. This segment centers around explicit precedents and concentrates that have been directed on reusing e-squander in nations, for example, China, Nigeria, Philippines, Brazil, and so forth.

\section{Lethal Chemicals in E-Waste}

An ongoing report demonstrated that $\mathrm{Au}, \mathrm{Pb}, \mathrm{Ag}$, and $\mathrm{Sb}$ were found in the dirt at a casual e-squander reusing site in the Philippines. Electronic gadgets contain plenty of segments and parts, numerous that house bits of dangerous synthetics that are destructive to people. Synthetic substances can start from substantial family unit machines, for example, iceboxes, washers, and dryers. Shopper hardware is likewise an expansive segment of electronic waste and incorporates TVs, mobile phones, PCs, screens, and notwithstanding wearing gear. The parts that make up these gadgets o en contain risky synthetic substances that thus end up going to creating nations. A portion of these part that adds to the poisonous waste incorporate batteries, circuit sheets, cathode-beam cylinders, and lead capacitors. Most of the e-squander is involved in iron and steel (half of the waste). Plastics and ferrous metals make up the following 21 and 13 percent, individually. Nonetheless, a considerable lot of these segments contain poisonous mixes like PCBs, dioxins, and overwhelming metals in their essential structures. Lead, Cadmium, Nickel, and Lithium alone are found in utilized batteries, much like the ones being mass-delivered in electric vehicles. Organophosphate fire retardants and plasticizers in pee tests of the general population living in an e-squander destroying the site. Follow metal contaminants from e-squander soils however not in the gushing because of adsorption to Fe/Mn oxides in the sub-layer soil.

Data innovation is a key player in the generation of unsafe synthetic compounds that originate from an assortment of segments, for the most part, PCs. One examination done on the effect of perilous e-squander in India has assessed that more than 30,000 PCs have progressed toward becoming decommissioned every year in Bangalore alone. The high transfer of PCs has developed in excess of 1,000 tons of plastics, 300 tons of lead, 0.23 huge amounts of mercury, 43 tons of nickel, and 350 tons of copper in Bangalore. In Bangladesh, at a shipyard in Chittagong, pollution tormented the close-by soil from synthetic substances that are usually found in electronic waste. Soil tests contained mixes, for example, "lead, mercury, cadmium, arsenic, antimony trioxide, polybrominated fire retardants, selenium, chromium, and cobalt".

Exploited people in creating nations are presented to risky synthetic substances in an assortment of ways. Casualties of electronic waste can be responded by direct presentation just as a backhanded introduction. The coordinate presentation can happen when the harmful synthetic compounds are breathed in, contacted by skin contact, or ingestion of the synthetic concoctions. A significant number of the synthetic concoctions found in electronic parts can without much of a stretch filter out into neighborhood water sources, discover their way in sustenance, and can undoubtedly be overwhelmed by the breeze and transported into the air. Mercury, an overwhelming metal found in indoor regulators, bright light bulbs, and other family unit things bioaccumulates in natural life, particularly angle when mercury is kept in the lakes and streams. While some fish are sheltered to eat, others end up dangerous to the point where little utilization can be extremely hurtful to human wellbeing.

Playing out these casual reusing strategies and transfer techniques specifically result in ecological debasement and negative biological system effects these harmful synthetic concoctions can remain in nature for extensive stretches of time and will keep on developing in fixation if the measure of e-squander keeps on expanding as it is presently.

Introduction Routes and Problematic impacts Electronic waste is difficult to discard. Hardware is not intended to be dismantled. Most hardware contains unsafe materials that require exceptional dealing with, for example, lead, mercury, arsenic, chromium, and cadmium. In spite of the hazard, many creating nations don't have appropriate directions and approaches set up to ensure the neighborhood individuals and condition. For instance, in Nigeria, valuable metals are expelled from circuit sheets by utilizing corrosive, and after that dumping them onto the ground or into streams. This absence of direction puts not just the general population dealing with the loss in danger, yet in addition the earth.

Concentrates on wellbeing impact of e-squander reusing rehearses have been performed as of late. The impact of esquander on urinary metabolites. Diminished immunization immunizer titers following presentation to various 
metals and metalloids in e-squander uncovered preschool kids. Human presentation to halogenated fire retardants (HFR) through dermal adsorption by skin wipe. Dermal assimilation would be a vital introduction course for HFR.

Regardless of the dangers and perils of dealing with e-squander, it is a path for local people to profit. The city of Guiyi, in China, utilizes more than 150,000 individuals. These individuals come up short on the best possible defensive hardware and open themselves to dangerous convergences of numerous hurtful synthetic concoctions. So as to gather valuable metals, different materials are signed or acidically expelled so as to uncover the more important materials. Poisons are discharged into the earth through transfer procedures, for example, copying, covering, dumping. Three normal transfer techniques incorporate landfills softening segments, cremation, which are all equipped for defiling water assets and causing air contamination issues. These poisons can advance into groundwater making water contamination issues for adjacent plants. The measure of cadmium present in one PDA battery can dirty up to $600 \mathrm{~m} 3$ of water.

The poisons presented to nature from e-squander transfer undermine nearby biological communities. One examination in Guiyi tried the encompassing paddy cultivate the soil and discovered dimensions of polybrominated diphenyl ethers (PDE) and polychlorinated di-benzo-p-dioxins that surpassed worldwide rules for agrarian regions. Overwhelming metals in the dirt can pollute plants. In the event that these plants are devoured by people, the overwhelming metals can, collect in human bodies and cause destructive impacts

Concentrates in Guiyi additionally discovered abnormal amounts of PDEs, lead, and copper in the towns street dust. Expanded residue levels relate to more elevated amounts of contamination and suspended solids. Residue tried in 2008 in Guiyi found to have lead and copper levels multiple times higher than encompassing regions without esquander dumping locales. Particulate issue from substantial metals noticeable all around can expand dangers of mortality and grimness. This hazard is most genuine for specialists, as the suspended solids will, in general, think inside the e-squander destroying workshop.

\section{Mindfulness BUILDING:}

The present mindfulness with respect to the presence and risks of e-squander is very low, incompletely in light of the fact that the e-squander being produced isn't as huge as in created nations. Pressing measures are required to address this issue.

The job of residents in e-squander the executives incorporates:

- Donating gadgets for reuse which broadens the lives of significant items and keeps them out of the waste administration framework for quite a while.

- While purchasing electronic items, selecting those that are made with less dangerous constituents, use reused substance, are vitality proficient, are intended for simple redesigning or dismantling, utilize negligible bundling and offer renting or reclaim choices.

End:

India is put in an extremely intriguing position. The need of great importance is a dire way to deal with the esquander peril by specialized and strategy level intercessions, execution and limit building and increment in broad daylight mindfulness to such an extent that it can change over this test into a chance to demonstrate the world that India is prepared to manage future issues and can set worldwide believable norms concerning natural and word related wellbeing.

The best option in contrast to this issue is the best possible gathering and control of utilized and undesirable gadgets. Just through reusing can these synthetic concoctions be securely contained. A large number of the materials can be utilized again for other modern applications while the unusable parts are viably put away or appropriately discarded in a way that has minimal measure of ramification for human wellbeing and the earth.

It requires an organized exertion with respect to the districts, private industry and people to keep electronic waste out of the landfill and out of incinerators. People spurred to reuse their utilized hardware will be bound to do as such. Private organizations supported and remunerated by neighborhood governments to give a method for reusing 
will see a money saving advantage in it. Districts should seize the opportunity to enhance the encompassing condition, diminishing the negative effect and making a superior world simultaneously.

E-squander is being created at accumulated at a fast rate in creating nations around the globe. This e-squander reusing issue should be routed to diminish the unsafe coming about impacts that the dangerous synthetic compounds in e-squander have on natural and human wellbeing. The current arrangements that creating nations have made so far have not been powerful in lessening the measure of casual reusing in light of the fact that there is a general absence of administration and authorization assets in these regions. Formal offices have not possessed the capacity to contend with the casual reusing. It is advantageous to exploit the current gathering system that the casual reusing part has set up as opposed to attempting to do the inconceivable by endeavoring to nullify it. A motivating force framework will in all probability be needed the casual recyclers be all the more eager to convey their gathered ewaste to the formal offices where it will be reused without bringing about negative effects to the earth and human wellbeing. Also, interest in the assets important to give authorization and supervision to the current and potential new approaches that will be set up ought to be executed. For instance, the limitation of e-squander importation should be controlled better so as to diminish the measure of e-squander being transported to these casual reusing territories. Thinking about future moderation techniques, one essential alternative is for makers and makers to end up increasingly associated with actualizing reclaim frameworks to reuse their electronic things appropriately.

\section{E-Waste Mitigation Recommendations}

So as to ease the natural and human wellbeing impacts happening from casual reusing strategies, creating nations have endeavored to utilize the approach. The United Nations Environmental Program made the Basel Convention on the Control of Transboundary Movements of Hazardous Wastes and Their Disposal which restricted the exchanging of unsafe waste between countries. Tragically, this arrangement, just as different approaches that creating nations made, was not successful in diminishing the measure of casual reusing in light of the fact that there is a general absence of administration and authorization assets. The Basel Convention likewise had numerous lawful escape clauses which enabled nations to keep trading to creating nations under "gift" or "reusing" purposes. Creating nations have endeavored to put resources into and empower formal office undertaking foundation to relieve the esquander issue. For instance, China put resources into around 100 formal office ventures inside the most recent 10 years. The formal offices couldn't rival the casual recyclers accumulation costs. Casual recyclers can present to multiple times higher the value that formal offices can on the grounds that the formal offices need to consider the costs that will be expected to reuse the materials appropriately. Notwithstanding enactment and formal office framework, the casual reusing area still reuses most of e-squander in creating nations. Consequently, there are a few factors that ought to be considered for future e-squander alleviation designs. With respect to future alleviation, the makers and makers need to end up progressively included by making and executing reclaim frameworks on their electronic gadgets. The buyers would then bring their utilized or crushed electronic things spirit to the producer where they can be disseminated to an office where the materials will be dealt with and discarded legitimately. Innovative work ought to likewise be improved the situation these makers and makers to utilize less unsafe materials in their electronic gadgets. Also, these electronic gadgets ought to be made in such an approach to make them less demanding to dismantle and to reuse the reusable materials. In this manner, a blend of these components would result in a progressively fruitful relief plan for creating nations later on.

\section{References:}

[1]. Sthiannopkao S, Wong MH (2013) Handling e-waste in developed and developing countries: Initiatives, practices, and consequences. Sci of the Tot Environ 463: 1147-1153.

[2]. Kumar A, Holuszko M, Espinosa DCR (2017) E-waste: An overview on generation, collection, legislation and recycling practices. Res Conser and Recyc 122: 32-42.

[3]. Garlapati VK (2016) E-waste in India and developed countries: Management, recycling, business and biotechnological initiatives. Renew and Sustain Ener Rev 54: 874-881.

[4]. An D, Yang Y, Chai X, Xi B, Dong L, et al. (2015) Mitigating pollution of hazardous materials from WEEE of China: Portfolio selection for a sustainable future based on multi-criteria decision making. Res Conser and Recyc 105: 198.

[5]. Song Q, Li J (2014) A systematic review of the human body burden of ewaste exposure in China. Environ Int 68: 8293.

[6]. Zhang WH, Wu YX, Simonnot MO (2012) Soil contamination due to ewaste disposal and recycling activities: A review with special focus on China. Pedos 22: 434-455.

[7]. Zhao G, Wang Z, Zhou H, Zhao Q (2009) Burdens of PBBs, PBDEs, and PCBs in tissues of the cancer patients in the e-waste disassembly sites in Zhejiang, China. Sci of Tot Environ 407: 4831-4837. 
[8]. Terazono A, Oguchi M, Yoshida A, Medina RP, Ballesteros FC (2016) Metal recovery and environmental impact by informal e-waste recycling sites in Philippines. Sustain Throu Innov Prod Lif Cyc Des, pp: 197-213.

[9]. Perkins BD, Nxele S (2014) E-waste: A Global Hazard, Annals of Global Health. Articl and Rev 80: 286-295.

[10]. Needhidasan S, Samuel M, Chidambaram R (2014) Electronic waste-an emerging threat to the environment of urban India. J of Environ Health Sci and Eng 12: 36.

[11].Lin X, Xu X, Zeng X, Huo X (2017) Decreased vaccine antibody titers following exposure to multiple metals and metalloids in e-waste-exposed preschool children. Environ Pollu 220: 354-363.

[12]. Cui JL, Luo CL, Tang CWY, Shan TS, Li XD (2017) Speciation and leaching of trace metal contaminants from ewaste contaminated soils. J of Hazard Mater 329: 150-158

[13].Alam M, Bahauddin KM (2015) E-Waste in Bangladesh: Evaluating the

[14]. Situation, Legislation and Policy and Way Forward with Strategy and Approach. PESD 9: 25-46.

[15].Kiddee P, Naidu R, Wong M (2013) Electronic waste management approaches An overview. Wast Manag 33: 12371250.

[16].Lu SY, Li YX, Zhang T, Cai D, Ruan JJ, et al. (2017) Effect of e-waste recycling on urinary metabolites of organophosphate flame retardants and plasticizers and their association with oxidative stress. Environ Sci Technol 51: 2427-2437.

[17].Liu X, Yu G, Gao Z, Wang B, Huang J, et al. (2017) Estimation of human exposure to halogenated flame retardants through dermal adsorption by skin wipe. Chemo 168: 272-278.

[18]. Acaroglu L (2013) Where Do Old Cellphones Go to Die? The New York Times.

[19]. Chi X (2011) Informal electronic waste recycling: A sector review with special focus on China. Wast Manag 31: 4.

[20].Davis J, Garb Y (2015) A model for partnering with the informal e-waste industry: Rationale, principles and a case study. Res Conser and Recyc 105:73.
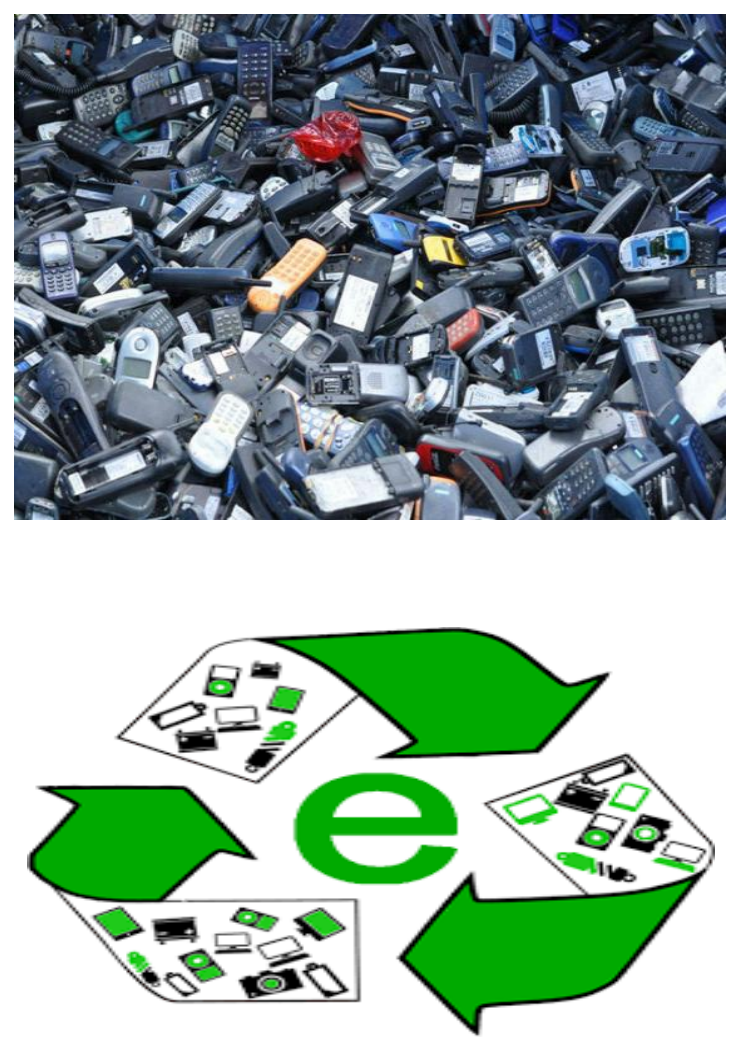